\title{
Sequential changes in susceptibility to Treponema pallidum of rabbits previously infected with Treponema paraluis-cuniculi
}

\author{
S GRAVES
}

From the Department of Microbiology, Monash University Medical School, Alfred Hospital, Prahran, Victoria, Australia

SUMMARY Rabbits immunised with virulent Treponema paraluis-cuniculi were challenged intradermally with graded doses of Treponema.pallidum at three, five, seven, 12, and 30 months to ascertain the level of protection to $T$ pallidum at various intervals after immunisation.

Rabbits challenged at three months after immunisation showed no protection against $T$ pallidum and developed syphilitic lesions significantly faster than the control rabbits, which suggests that the former rabbits were immunosuppressed. Some protection was evident at five and seven months after immunisation, as fewer inoculation sites developed syphilitic lesions with challenges of $10^{3}, 10^{2}$, and $10 \mathrm{~T}$ pallidum and lesions developed significantly slower with $10^{6}$ challenge. Two rabbits showed significant protection at 12 months after immunisation but a third, presumably still immunosuppressed, developed lesions significantly faster than the control rabbits after challenge. At 30 months after immunisation one rabbit was completely protected and developed no lesions after challenge; the other rabbit showed only partial protection against challenge with $10^{4}, 10^{3}$, and $10^{2}$ but complete protection against challenge with $10 \mathrm{~T}$ pallidum.

$T$ paraluis-cuniculi appeared to induce a state of immunosuppression by three months after infection; in one rabbit this may have been 12 months. In most immunised rabbits, however, limited cross-protection to low challenge doses of $T$ pallidum developed by five months and was also detectable at seven and 12 months. Only one rabbit was completely resistant to challenge with $10^{4} \mathrm{~T}$ pallidum after 30 months and another was only partly immune. Thus, $T$ paraluis-cuniculi infection does not produce a rapid pronounced cross-immunity to $T$ pallidum in rabbits, which may thus limit its usefulness as a vaccine against syphilis.

\section{Introduction}

Treponema paraluis-cuniculi, the causative agent of rabbit venereal spirochaetosis, is closely related to the bacterium that causes human syphilis, Treponema pallidum. ${ }^{1}$ It was first suggested as a potential vaccine against syphilis in $1921^{2}$ and subsequent studies have shown that rabbits immunised or venereally infected with $T$ paraluis-cuniculi show some protection against challenge with $T$ pallidum. ${ }^{34}$ However, the rate neither of development of immunity to $T$ paraluis-cuniculi itself

Address for reprints: Dr S Graves, Department of Microbiology, Monash University Medical School, Alfred Hospital, Prahran, Victoria, Australia 3181

Accepted for publication 26 March 1980 nor of cross-immunity to $T$ pallidum has been studied in rabbits infected with $T$ paraluis-cuniculi. The rapid development of immunity to $T$ pallidum is obviously important if $T$ paraluis-cuniculi is to be seriously considered as a vaccine against human syphilis. It is known that immunity to $T$ pallidum in human and experimental rabbit syphilis is very slow to develop. ${ }^{15}$ Does a similar delay occur in rabbits infected with $T$ paraluis-cuniculi and challenged with $T$ pallidum?

\section{Materials and methods}

$T$ paraluis-cuniculi (strain 8816) was obtained from the Center for Disease Control, Atlanta, Georgia, USA (by courtesy of Dr A Balows). It was routinely 
grown in rabbits by intratesticular inoculation and the infection allowed to develop for about one month, by which time a mild orchitis had usually developed. The treponemes were harvested using a technique and anaerobic medium previously described. ${ }^{6}$

\section{INFECTION WITH T PARALUIS-CUNICULI}

All test rabbits to be challenged with $T$ pallidum at three, seven, and 12 months were infected intradermally with $2 \times 10^{7} T$ paraluis-cuniculi at one site on the shaved back. The inoculation site was kept shaved for the duration of the experiment or until the lesion had spontaneously healed.

Two test rabbits to be challenged at five months were inoculated intradermally with $10^{5} T$ paraluiscuniculi (as above) and one rabbit intratesticularly with the same inoculation.

One test rabbit $(E)$ to be challenged at 30 months was inoculated intratesticularly with $10^{6} T$ paraluiscuniculi and the other rabbit (D) had the inoculum placed on his genital mucosa (that is, under the prepuce, intraurethrally, and on the glans penis) without breaking the surface of the skin, so as to simulate a venereal mode of infection.

\section{CHALLENGE WITH T PALLIDUM}

$T$ pallidum was grown in male rabbits by inoculating $5 \times 10^{7}$ treponemes into each testis and harvesting them 10 to 14 days later, by which time marked orchitis had developed. The treponemes, harvested in an anaerobic maintenance medium, ${ }^{6}$ were diluted to a series of concentrations such that the required inoculum could be given in $0.1 \mathrm{ml}$.

Each rabbit had its back shaved and marked into a grid of $15-\mathrm{mm}$ squares (usually $3 \times 4$ ), and triplicate doses $(0 \cdot 1 \mathrm{ml})$ of each of $10^{4}, 10^{3}, 10^{2}$, and $10 T$ pallidum were inoculated intradermally.

The rabbits' backs were kept shaved and the rabbits fed antibiotic-free food and water and housed at $16-19^{\circ} \mathrm{C}$. After challenge inoculation they were examined daily for the development of syphilitic lesions until day $\mathbf{3 0}$ and twice weekly thereafter until the end of the observation period.

Rabbits challenged at five months were inoculated with $10^{6}, 10^{5}, 10^{4}$, and $10^{3} T$ pallidum. This experiment was the first one performed in the series before it was decided to test protection with lower challenge doses $\left(10^{4}, 10^{3}, 10^{2}, 10\right)$.

\section{MONITORING OF LESIONS}

The development of a syphilitic lesion on challenge with $T$ pallidum was detected as induration in the skin at the inoculation site. In some cases these lesions were scraped and shown by darkfield microscopy to contain treponemes. The latent period of infection was taken as the time, in days, between inoculation and the first appearance of the indurated lesion. The rate of growth of $T$ pallidum (and the subsequent infiltration of host mononuclear cells into the site) is a measure of the level of pre-existing immunity in the host to the bacterium. ${ }^{1}$ In the host the absence of a lesion represents substantial immunity to that particular challenge dose, while the slower development of a lesion (which is usually also smaller in size) represents partial immunity to $T$ pallidum.

Results were recorded as the proportion of $T$ pallidum inoculation sites that developed into syphilitic lesions, together with the latent period of the challenge infection, in the test rabbits compared with the control rabbits. Each test and control group contained three rabbits, except the group challenged at $\mathbf{3 0}$ months, which comprised two rabbits.

\section{SEROLOGICAL MONITORING}

The rapid plasma reagin (RPR) test was used and carried out according to the manufacturer's instructions (Commonwealth Serum Laboratories, Melbourne, Australia). The $T$ pallidum haemagglutination assay (TPHA) was performed using the kit produced by the Fujizoki Pharmaceutical Company Ltd according to the manufacturer's instructions. Only titres greater than 1/80 were considered positive. Known positive and negative control sera were included in each test series.

\section{STATISTICAL METHOD}

Student's $t$ test was used.

\section{Results}

\section{CHALLENGE AT THREE MONTHS}

No protection at all was detected. Even with a very low challenge of $10 \mathrm{~T}$ pallidum, all inoculation sites developed lesions (table). The latent periods of the challenge infections in the test rabbits were significantly shorter than in the control rabbits (table) suggesting faster growth of $T$ pallidum in the immunised rabbits rather than any protection.

\section{CHALLENGE AT FIVE MONTHS}

No protection was evident with $10^{5}$ or $10^{4}$ challenges of $T$ pallidum. Some protection was detected with $10^{6}$ challenge as shown by a significantly longer latent period. However, only with $10^{3}$ challenge was good protection evident by the absence of lesions in the immunised rabbits during the observation period of 219 days (table).

\section{CHALLENGE AT SEVEN MONTHS}

No protection was detected with $10^{4} T$ pallidum challenge and the latent period of infection was 
TABLE Development of syphilitic lesions in rabbits challenged with Treponema pallidum at varying intervals after previous infection with Treponema paraluis-cuniculi and in control rabbits

\begin{tabular}{|c|c|c|c|c|c|c|}
\hline \multirow{2}{*}{$\begin{array}{l}\text { Interval since } \\
T \text { paraluis- } \\
\text { cuniculi infection } \\
\text { (months) }\end{array}$} & \multirow{2}{*}{$\begin{array}{l}\text { Challenge } \\
\text { dose (id) } \\
\text { of } \\
\text { T pallidum }\end{array}$} & \multicolumn{2}{|c|}{$\begin{array}{l}\text { No of inoculation sites } \\
\text { developing syphilitic lesions }\end{array}$} & \multicolumn{2}{|c|}{$\begin{array}{l}\text { Latent period (days) between } \\
\text { inoculation and lesion (mean } \pm S D)\end{array}$} & \multirow{2}{*}{$\begin{array}{l}\text { Comments } \\
\text { (test rabbits) }\end{array}$} \\
\hline & & Control rabbits & Test rabbits* & Control rabbits & Test rabbits* & \\
\hline 3 & $\begin{array}{l}10^{4} \\
10^{3} \\
10^{2} \\
10\end{array}$ & $\begin{array}{l}9 / 9 \\
9 / 9 \\
9 / 9 \\
9 / 9\end{array}$ & $\begin{array}{l}9 / 9 \\
9 / 9 \\
9 / 9 \\
9 / 9\end{array}$ & $\begin{array}{l}12 \cdot 1 \pm 1 \cdot 1 \\
14 \cdot 4 \pm 0 \cdot 9 \\
17 \cdot 4 \pm 1 \cdot 2 \\
21 \cdot 1 \pm 1 \cdot 5\end{array}$ & $\left.\begin{array}{r}3 \cdot 9 \pm 1 \cdot 4 t \\
5 \cdot 2 \pm 1 \cdot 3 t \\
8 \cdot 7 \pm 2 \cdot 0 t \\
12 \cdot 7 \pm 1 \cdot 6 t\end{array}\right\}$ & $\begin{array}{l}\text { No protection: } \\
\text { possible immuno- } \\
\text { suppression }\end{array}$ \\
\hline 5 & $\begin{array}{l}10^{6} \\
10^{5} \\
10^{4} \\
10^{3}\end{array}$ & $\begin{array}{l}6 / 6 \\
6 / 6 \\
6 / 6 \\
5 / 6\end{array}$ & $\begin{array}{l}6 / 6 \\
5 / 6 \\
5 / 6 \\
0 / 6\end{array}$ & $\begin{array}{r}5 \cdot 3 \pm 0 \cdot 8 \\
7 \cdot 8 \pm 0 \cdot 8 \\
15 \cdot 0 \pm 1 \cdot 3 \\
21 \cdot 4 \pm 3 \cdot 0\end{array}$ & $\begin{array}{r}8 \cdot 7 \pm 0 \cdot 8 \neq \\
13 \cdot 0 \pm 13 \cdot 0 \\
13 \cdot 2 \pm 3 \cdot 9\end{array}$ & $\begin{array}{l}\text { Some protection } \\
\text { No protection } \\
\text { Protection }\end{array}$ \\
\hline 7 & $\begin{array}{l}10^{4} \\
10^{3} \\
10^{2} \\
10\end{array}$ & $\begin{array}{l}9 / 9 \\
9 / 9 \\
9 / 9 \\
8 / 9\end{array}$ & $\begin{array}{l}9 / 9 \\
5 / 9 \\
5 / 9 \\
2 / 9\end{array}$ & $\begin{array}{r}9 \cdot 6 \pm 1 \cdot 5 \\
11 \cdot 1 \pm 1 \cdot 5 \\
12 \cdot 8 \pm 2 \cdot 0 \\
18 \cdot 5 \pm 5 \cdot 2\end{array}$ & $\begin{array}{c}5 \cdot 6 \pm 0 \cdot 5 \dagger \\
9 \cdot 4 \pm 1 \cdot 7 \\
11 \cdot 0 \pm 0 \cdot 7 \\
15 \cdot 5 \pm 2 \cdot 1\end{array}$ & $\begin{array}{l}\text { No protection } \\
\text { Some protection }\end{array}$ \\
\hline \multirow[t]{4}{*}{12} & $10^{4}$ & $9 / 9$ & $6 / 6(A \& B) 3 / 3(C)$ & $13 \cdot 2 \pm 1 \cdot 3$ & \multirow{4}{*}{$\begin{array}{c}22 \cdot 0 \pm 1 \cdot 7(\mathrm{~A} \& \mathrm{~B}) \neq \\
5 \cdot 0 \pm 0(\mathrm{C}) \dagger \\
22 \cdot 5 \pm 3 \cdot 1(\mathrm{~A} \& \mathrm{~B}) \neq \\
6 \cdot 0 \pm 1 \cdot 0(\mathrm{C}) \dagger \\
24 \cdot 8 \pm 2 \cdot 6(\mathrm{~A} \& \mathrm{~B}) \neq \\
11 \cdot 0 \pm 4 \cdot 6(\mathrm{C}) \dagger \\
22(\mathrm{~A} \& \mathrm{~B}) \\
17(\mathrm{C})\end{array}$} & Limited protection \\
\hline & $10^{3}$ & $9 / 9$ & $6 / 6(A \& B) 3 / 3(C)$ & $14 \cdot 8 \pm 1 \cdot 3$ & & $\begin{array}{l}\text { in } 2 / 3 \text { rabbits } \\
\text { (A\&B): no }\end{array}$ \\
\hline & $10^{2}$ & $9 / 9$ & $5 / 6(\mathrm{~A} \& \mathrm{~B}) 3 / 3(\mathrm{C})$ & $18 \cdot 1 \pm 4 \cdot 0$ & & $\begin{array}{l}\text { protection } \\
\text { (possible immuno- }\end{array}$ \\
\hline & 10 & $6 / 9$ & $1 / 6(\mathrm{~A} \& \mathrm{~B}) 1 / 3(\mathrm{C})$ & $25 \cdot 3 \pm 7 \cdot 3$ & & $\begin{array}{l}\text { suppression) } \\
\text { in } 1 / 3 \text { rabbits (C) }\end{array}$ \\
\hline \multirow[t]{2}{*}{30} & $\begin{array}{l}10^{4} \\
10^{3} \\
10^{2}\end{array}$ & $\begin{array}{l}8 / 8 \\
8 / 8 \\
8 / 8\end{array}$ & $\begin{array}{l}2 / 4(D) 0 / 4(E) \\
4 / 4(D) 0 / 4(E) \\
4 / 4(D) 0 / 4(E)\end{array}$ & $\begin{array}{l}11 \cdot 4 \pm 0 \cdot 5 \\
12 \cdot 4 \pm 0 \cdot 5 \\
14 \cdot 7 \pm 2 \cdot 0\end{array}$ & \multirow[t]{2}{*}{$\begin{array}{l}85 \pm 32(D) \neq \\
85 \pm 35(D) \neq \\
93 \pm 22(D) \neq\end{array}$} & \multirow{2}{*}{$\begin{array}{l}\text { Protection in } \\
\text { rabbit }(\mathrm{E}) \text { : limited } \\
\text { protection in } \\
\text { rabbit (D) } \\
\text { Protection }\end{array}$} \\
\hline & 10 & $6 / 8$ & $0 / 4(D) 0 / 4(E)$ & $20 \cdot 7 \pm 1 \cdot 0$ & & \\
\hline
\end{tabular}

*Immunised rabbits challenged at 12 and 30 months responded quite differently and consequently results could not be averaged validly. tLesions developed significantly faster in test rabbits than in control rabbits $(P<0.05)$.

₹Lesions developed significantly slower in test rabbits than in control rabbits $(P<0 \cdot 05)$.

shorter than in the control rabbits (table). This was a similar result to that with challenge at three months. However, the lesions were much more transient in the immunised rabbits compared with in the controls; they disappeared on average only $\mathbf{9 \cdot 3}$ days after their first appearance. Lesions in the control rabbits, however, persisted for many weeks and were still large at the end of the observation period (day 34). This implied that some level of immunity was present in the immunised rabbits and that the faster appearance of lesions after challenge with $T$ pallidum may have been related to the possible presence of hypersensitivity in the immunised rabbits.

With challenges of $10^{3}, 10^{2}$, and $10 \mathrm{~T}$ pallidum some protection was evident, as fewer inoculation sites developed into syphilitic lesions, which themselves were transient in the immunised rabbits (table). With a $10^{3}$ challenge lesions persisted for $7 \cdot 4$ days (mean), with a $10^{2}$ challenge for only 1.6 days (mean), and with a 10 challenge for 8.5 days (mean). Furthermore, in all cases the lesions in the immunised rabbits were considerably smaller than those in the control rabbits.

\section{CHALLENGE AT 12 MONTHS}

Of the three test rabbits in this group, two of them (A and $B$ ) showed lesions with significantly longer latent periods (table), implying some level of immunity to $T$ pallidum challenges of $10^{4}, 10^{3}$ and $10^{2}$, while one rabbit $(C)$ showed lesions with significantly shorter latent periods somewhat similar to the observations in the group challenged at three months.

Partial protection against $T$ pallidum was evident in all three rabbits with a 10 challenge, as fewer inoculation sites developed syphilitic lesions compared with the control rabbits.

\section{CHALLENGE AT 30 MONTHS}

One rabbit (E) was apparently completely protected as no lesions developed with any $T$ pallidum challenge dose (table). However, the regional lymph nodes were not examined, and the rabbit may have had an asymptomatic infection. The other rabbit (D) showed some protection with challenges of $10^{4}, 10^{3}$, and $10^{2} T$ pallidum, as manifested by greatly extended latent periods of infection. With a 10 challenge no lesions appeared by day 163 , the end of the observation period.

ANTIBODY TITRES IN TEST RABBITS

All test rabbits had developed positive results to the RPR test and TPHA when first tested serologically three months after infection with $T$ paraluis-cuniculi. TPHA titres ranged from 1/640 to 1/5120. 


\section{Discussion}

By examining the sequential development of crossimmunity to $T$ pallidum in rabbits infected with $T$ paraluis-cuniculi for up to 30 months after immunisation, we have shown that protection is very slow to develop, being first detected five months after immunisation, and is of a very low level. Usually, only partial protection to low challenge doses of $T$ pallidum was detected. The long delay in appearance of any immunity to $T$ pallidum, and a previous observation ${ }^{7}$ that human infection with $T$ paraluis-cuniculi gives rise to only transient and low concentrations of antibodies to $T$ pallidum, strongly suggests that this bacterium will not be suitable for a vaccine strain against human syphilis.

In addition, the period of marked immunosuppression, detected in all three rabbits at three months and in one of three rabbits at 12 months after immunisation and manifested by increased rates of growth of challenge $T$ pallidum in the immunised rabbits compared with in the control rabbits, means that the recipient of a $T$ paraluis-cuniculi vaccine would be more susceptible to $T$ pallidum (rather than more resistant) during the early months after immunisation. Such a situation would be the opposite to the desired effect. Furthermore, the immunosuppression may render the vaccinated subject more susceptible to other microbial pathogens, as was observed when a human volunteer infected with $T$ paraluis-cuniculi developed a severe respiratory infection 17 weeks after treponemal infection. $^{7}$

The slow onset of immunity and the transient period of immunosuppression that was detected in this study parallels similar (although better studied) phenomena observed in human and rabbit infections with $T$ pallidum. Immunity in syphilis develops slowly ${ }^{15}$ and in rabbits is only complete about three months after infection. Considerable evidence suggests that immunosuppression and other immunological aberrations occur during early syphilis, possibly because of a transient loss of effective cell-mediated immunity. ${ }^{8-19}$ In this respect $T$ paraluis-cuniculi may be quite similar to $T$ pallidum in its ability to induce a state of immunosuppression in the host. Furthermore, experimental immunisation of rabbits with killed $T$ pallidum vaccines also resulted in faster development of lesions ${ }^{20}$ and the presence of more $T$ pallidum in the lesions ${ }^{21}$ of immunised rabbits after challenge with virulent $T$ pallidum than in those of the controls. The future development of an effective vaccine against syphilis will probably require the removal of the immunosuppression-inducing component from whatever treponemal species is used as the immunising agent.

This work was supported by grants from the National Health and Medical Research Council, the Utah Foundation, the Danks Trust, the estate of the late George Adams, the Ian Potter Foundation, and Monash University, from whom funds are gratefully acknowledged.

\section{References}

1. Turner TB, Hollander DH. Biology of the treponematoses. Monograph series No 35, Geneva: World Health Organisation, G 1957.

2. Levaditi C, Marie A. Nicolau S. Virulence pour l'homme du spirochète de la spirillose spontanée du lapin. C R Acad Sci (D) (Paris) 1921; 172:1542-3.

3. Turner TB, McLeod CP, Updyke EL. Cross-immunity in experimental syphilis, yaws and venereal spirochaetosis of rabbits. Am J Hyg 1947; 46:287-95.

4. Graves SR. Susceptibility of rabbits venereally infected with $\mathbb{D}$ Treponema paraluis-cuniculi to superinfection with Treponema pallidum $\mathrm{Br} J$ Vener Dis 1980;56:387-9.

5. Chesney AM. Immunity in syphilis. Medicine Monographs $1927 ; 12$.

6. Graves SR, Sandok PL, Jenkin HM, Johnson RC. Retention $\overrightarrow{0}$ of motility and virulence of Treponema pallidum (Nichols $\infty$ strain) in vitro. Infect Immun 1975; 12:1116-20.

7. Graves SR, Downes J. Experimental infection of human volunteer with rabbit-virulent Treponema paraluis-cuniculi. Br J Vener Dis 1981; 57:7-10.

8. Levene GM, Turk JL, Wright DJ, Grimble AG. Reduced lymphocyte transformation due to a plasma factor in patients with active syphilis. Lancet 1969, ii:246-7.

9. Fulford $\mathrm{KW}$, Brostoff $\mathrm{J}$. Leucocyte migration and cell mediated immunity in syphilis. Br J Vener Dis 1972; 48:483-8.

10. Wright DJ, Grimble AS. Why is the infectious stage of syphilis prolonged? Br J Vener Dis 1974; 50:45-9.

11. Friedman P, Turk JL. A spectrum of lymphocyte responsiveness in human syphilis. Clin Exp Immunol 1975;21:59-64.

12. Musher D, Schell R, Knox J. The immunology of syphilis. Int $J$ Dermatol 1976; 15: 566-76.

13. From E, Thestrup-Pedersen $K$, Thulin $H$. Reactivity of lymphocytes from patients with syphilis towards $T$ pallidum antigen in the leucocyte migration and lymphocyte transformation tests. Br J Vener Dis 1976; 56:224-9.

14. Wicher $\mathrm{V}$, Wicher $\mathrm{K}$. In-vitro cell response of Treponema pallidum infected rabbits. I Lymphocyte transformation. Clin Exp Immunol 1977; 29:480-6.

15. Wicher $\mathrm{V}$, Wicher $\mathrm{K}$. In-vitro cell response of Treponema pallidum infected rabbits. II Inhibition of lymphocyte response to phytohaemagglutinin by serum of $T$ pallidum infected $D$ rabbits. Clin Exp Immunol 1977; 29:487-95.

16. Wicher $\mathrm{V}$, Wicher $\mathrm{K}$. In-vitro cell response of Treponema pallidum infected rabbits. III Impairment in production of $N$ lymphocyte mitogenic factor. Clin Exp Immunol 1977; 29:496-500.

17. Pavia CS, Folds JD, Baseman JB. Cell-mediated immunity during syphilis; a review. Br J Vener Dis 1978;54: 144-50.

18. Baughn RE, Musher DM. Aberrant secondary antibody responses to sheep erythrocytes in rabbits with experimental syphilis. Infect Immun 1979; 25: 133-8.

19. Bey RF, Johnson RC, Fitzgerald TJ. Suppression of lymphocyte response to concanavalin $A$ by mucopolysaccharide material from Treponema palliduminfected rabbits. Infect Immun 1979; 26:64-9.

20. Jones AM, Zeigler JA, Jones RH. Experimental syphilis vaccines in rabbits. I Differential protection with an adjuvant spectrum. Br J Vener Dis 1976; 52:9-17.

21. Waring GW, Fleming WL. Further attempts to immunize rabbits with killed Treponema pallidum. Am J Syph 1951;35:568-72. 